\title{
دراسة اقتصادية للميزان التجاري في الكويت
}

\author{
محمد علي سكران محزم السهلي \\ باحث دكتوراه بمعهد البحوث والدراسات الأفريقية - جامعة أسوان
}

محمد عبد الحفيظ محمد

أستاذ الإقتصاد الزراعى - كلية الزراعة - جامعة سوهاج

حسن موسي رضوان

مدرس الاقتصاد الزراعي بالمعهد العالي للتعاون والإرشاد الزراعي بأسيوط 


\section{الملخص:}

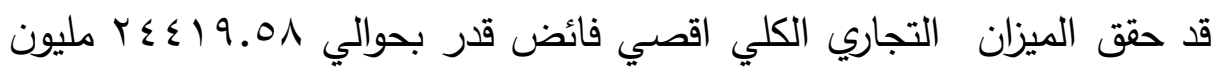

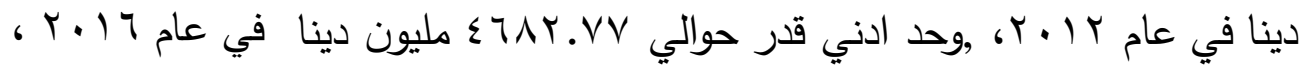
وبلغ متوسط الفائض خلال فترة الدر اسة حو الي هـ.9 19 ـ ـ المليون دينا. ويعبر مؤشر معدل التغطية للتجارة للخارجية بصفة أساسية عن كفاءة التجارة الخارجية الكلية، وقدرتها على تغطية نفقات الواردات من حصيلة الصادرات ، كما يشير ايضا الى الوضع النسبي للكويت في عملية التبادل الدولي أي مدى تحكمها في وارداتها، ويتبين من الجدول رقم ( () أن معدل تغطية الصادرات الكلية للواردات الكلية

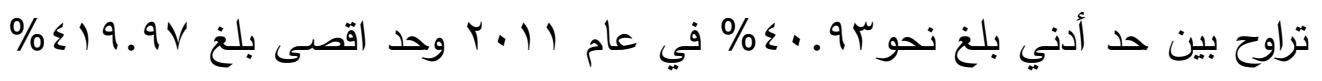
في عام r I ـ ب وبلغ متوسط معدل تغطية الصادرات للواردات خلال فترة الدراسة نحو

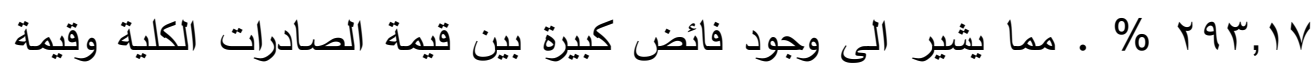
الواردات الكلية تكون في صالح الموازنة التجارية بالدولة، وأنها لا تمثل اعتماداً على الخارج·

$$
\text { الكلمات الإفتتاحية: الميزان التجارى - الصادرات - الواردات }
$$

\section{Abstract}

An Economic Study of the Balance of Trade in Kuwait 
The total trade balance achieved a maximum surplus estimated at about 24419.58 million dinars in 2012, and a minimum of about 4682.77 million dinars in 2016, and the average surplus during the study period was about 14019.35 million dinars.

The index of the coverage rate of foreign trade mainly expresses the efficiency of total foreign trade and its ability to cover import expenditures from the proceeds of exports. It also indicates the relative position of Kuwait in the international exchange process, i.e. the extent of its control over its imports. Table No. (1) shows that the coverage rate is Total exports to total imports ranged between a minimum of about $40.93 \%$ in 2011 and a maximum of $419.97 \%$ in 2012, and the average rate of export coverage to imports during the study period was about 293.1\%. This indicates the existence of a large surplus between the value of total exports and the value of total imports in favor of the country's trade budget, and that it does not represent dependence on the outside. 
تلعب التجارة الخارجية دورا كبيراً في عملية التنمية الاقتصادية في كثير من دول العالم وبخاصة في دول مجلس التعاون الخليجي، لأنها تدعم التوسع وتثبع الرغبات الاستهلاكية المتزايدة للسكان المنطقة. وبما أن العالم يسعي اليوم بكافة الطرق الي التوسع في التجارة الخارجية للأهمية البالغة التي تكتسبها هذه الأخيرة إضافة الي أن المناخ الإقتصادي الدولي في تطور مستمر نحو الاتحاد والتكامل الاقتصادي مما استوجب علي الدول النامية ومن بينها الكويت مواكبة هذا التطور الحاصل. الكويت كباقي دول العالم التي سعت لمواكبة هذا التطور وبعد أن ورثت عقب استقلالها نظاما سيطر علية اقتصاد فرنسا في مجال المبادلات التجارية ولكون قطاع التجارة الخارجية المتنفس الوحيد لما يوفره من مدخلات تسمح بتغطية متطلبات الدولة إعتمادا علي صادراتها من المواد الأولية ( البترول والغاز)، رأت الدولة أن تسير هذا القطاع بانتهاج سياسات مختلفة تتلاءم مع المرحلة الإقتصادية التي تمر بها البلاد فعدد خلال مسيرتها التنموية الي فرض الرقابة علي التجارة الخارجية في المرحلة أولي ثم احتكارها في المرحلة ثانية، ولكن بعد أزمة الدولار وأزمة النفط في عام 1919 وانخفاض اسعار المحروقات التي انعكست بنقص إيرادات الدولة من التجارة الخارجية، حيث تعتبر المحروقات العنصر الأساسي في الايرادات الدولة من التجارة الخارجية. 
رغم الأهمية التي يكتسبها الميزان التجاري كقوة دافعة للتمية الاقتصادية الا أن

هناك بعض المتغيرات والتحولات الاقتصادية التي لها أثر علي وضعيته وبالتالي يجب أخذها في الحسبان، ماهي أهم التحليلات التي يمكن أن نقدمها للتغيرات التي حدثت

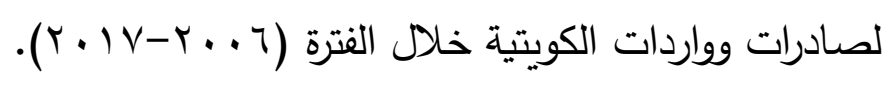
التساؤلات الفرعية: - (- ماهو

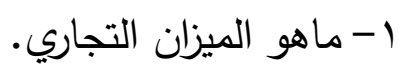

r- ماهو واقع تطبيق استراتيجات كل من الاستيراد والتصدير في الكويت.

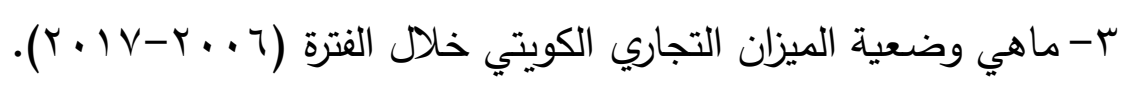

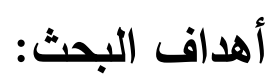

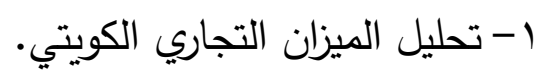

r-معرفة مدي تأثر وضعية الميزان التجاري الكويتي بالمتغيرات والتحولات الاقتصادية.

r-معرفة الدور الذي تلعبه كل من الصادرات والواردات في تحديد وضعية الميزان التجاري.

منهج ووسائل جمع البيانات للاراسة: 
اعتمدت الدراسة علي المنهج الوصفي، واستخدامها في إبراز أهم الاحصائيات التي تخص الميزان التجاري الجزائري من خلال تحليل التركيبة السلعية لكل من الصادرات والواردات. حدود الدراسةة:

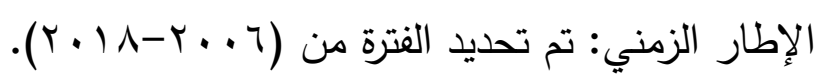
الإطار المكاني: تستهدف الدراسة الكويت.

الإطار الموضوعي: الدراسة الحالية تقتصر علي دراسة وتحليلة الميزان

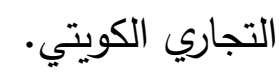
نتائج الاراسة: المبحث الأول: تحليل تطور الصادرات والواردات في الكويت: سنحاول من خلال هذا المبحث تحليل تطور الصادرات والواردات في الكويت من ناحية ، وتطور التركيبة السلعية للصادرات، وتطور التركيبة السلعية للواردات في الكويت:

المطلب الأول: تحليل تطور الميزان التجاري في الكويت: تثير البيانات الواردة في جدول رقم ( ) والثكل رقم (1) إلي أن إجمالي قيمة التجارة الخارجية الكلية للكويت خلال فترة الدراسة تراوحت بين حد ادني بلغ حوالي

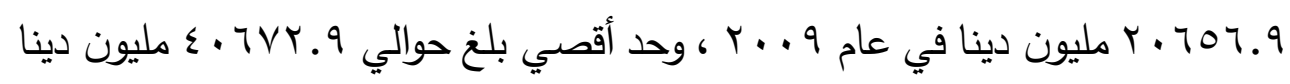




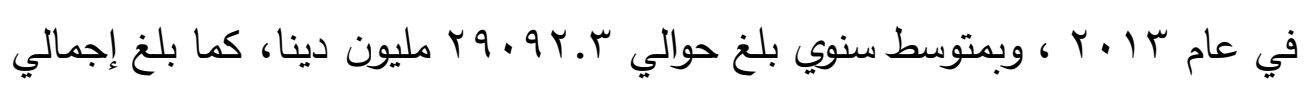

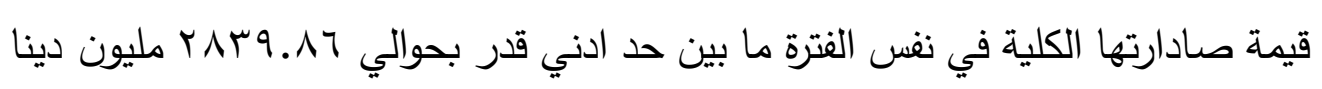

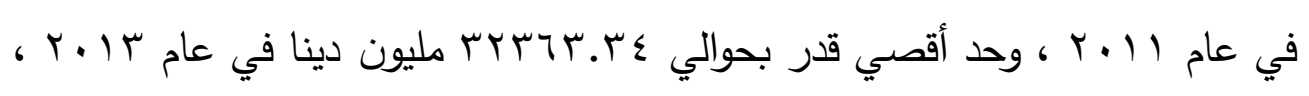

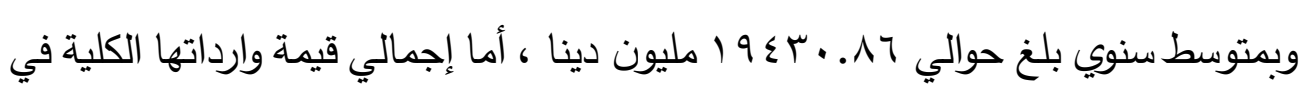
نفس الفترة فقد تراوحت ما بين حد ادني قدر بحوالي •.0.0.0 مليون دينا في عام

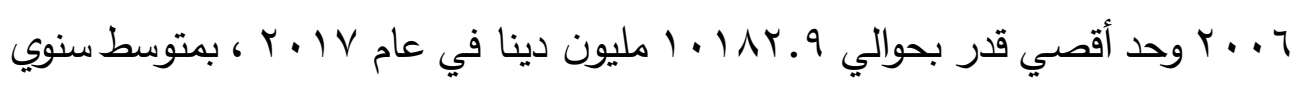

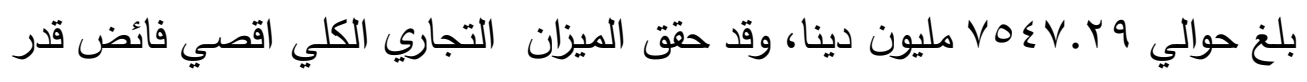

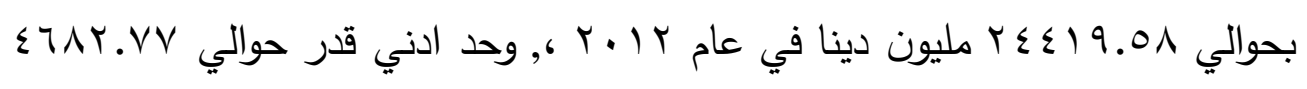
مليون دينا في عام 17 ـ ب ، وبلغ متوسط الفائض خلال فترة الدراسة حوالي

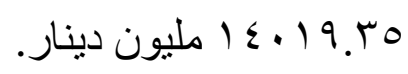
ويعبر مؤشر معدل التغطية للتجارة للخارجية بصفة أساسية عن كفاءة التجارة الخارجية الكلية، وقدرتها على تغطية نفقات الواردات من حصيلة الصادرات ، كما يشير ايضا الى الوضع النسبي للكويت في عملية التبادل الدولي أي مدى تحكمها في وارداتها، ويتبين من الجدول رقم (1) أن معدل تغطية الصادرات الكلية للواردات الكلية

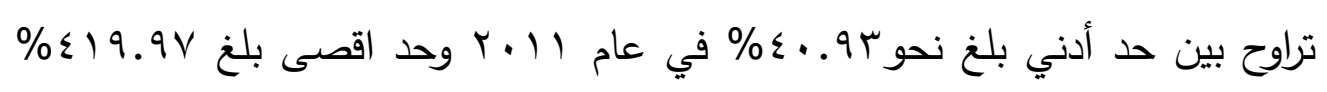
في عام r ب ـ ب وبلغ متوسط معدل تغطية الصادرات للواردات خلال فترة الدراسة نحو

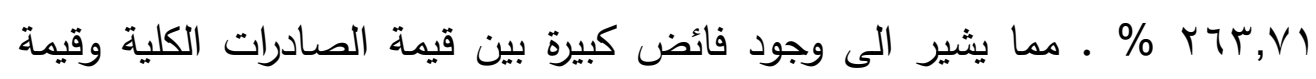


الواردات الكلية تكون في صالح الموازنة التجارية بالدولة، وأنها لا تمثل اعتماداً على

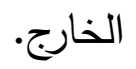

\section{الجدول رقم (1) تطور قيمة الصادرات والواردات للكويت خلال الفترة

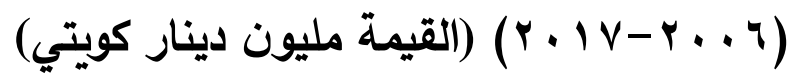

\begin{tabular}{|c|c|c|c|c|c|}
\hline معلية & الميزان التجاري & جملة التجارة & الواردات & الصادرات & السنوات \\
\hline 324.95 & 11248.819 & 21249.833 & 5000.507 & 16249.326 & 2006 \\
\hline 293.12 & 11705.231 & 23828.169 & 6061.169 & 17766.700 & 2007 \\
\hline 351.26 & 16781.063 & 30138.459 & 6678.698 & 23459.761 & 2008 \\
\hline 255.19 & 9211.969 & 20656.989 & 5852.246 & 14934.537 & 2009 \\
\hline 276.35 & 11460.637 & 24457.850 & 6498.607 & 17959.244 & 2010 \\
\hline 40.93 & 21401.795 & 35277.925 & 6938.065 & 2839.860 & 2011 \\
\hline 419.97 & 24419.582 & 39682.979 & 7631.699 & 32051.281 & 2012 \\
\hline 389.50 & 24054.496 & 40672.188 & 8308.846 & 32363.342 & 2013 \\
\hline 324.33 & 19807.176 & 37465.812 & 8829.318 & 28636.494 & 2014 \\
\hline 174.75 & 6964.107 & 25596.311 & 9316.102 & 16280.208 & 2015 \\
\hline 150.51 & 4682.773 & 23221.389 & 9269.308 & 13952.081 & 2016 \\
\hline 163.77 & 6494.543 & 26860.477 & 10182.967 & 16677.510 & 2017 \\
\hline 200.57 & 10926.65 & 32416.039 & 10777.687 & 21617.352 & 2018 \\
\hline 263.71 & 14019.35 & 29092.37 & 7547.294 & 19430.86 & المتوسط \\
\hline
\end{tabular}

المصدر:الادارة المركزية للاحصاء، إحصاءات التجارة الخارجية، الكويت، أعداد

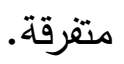




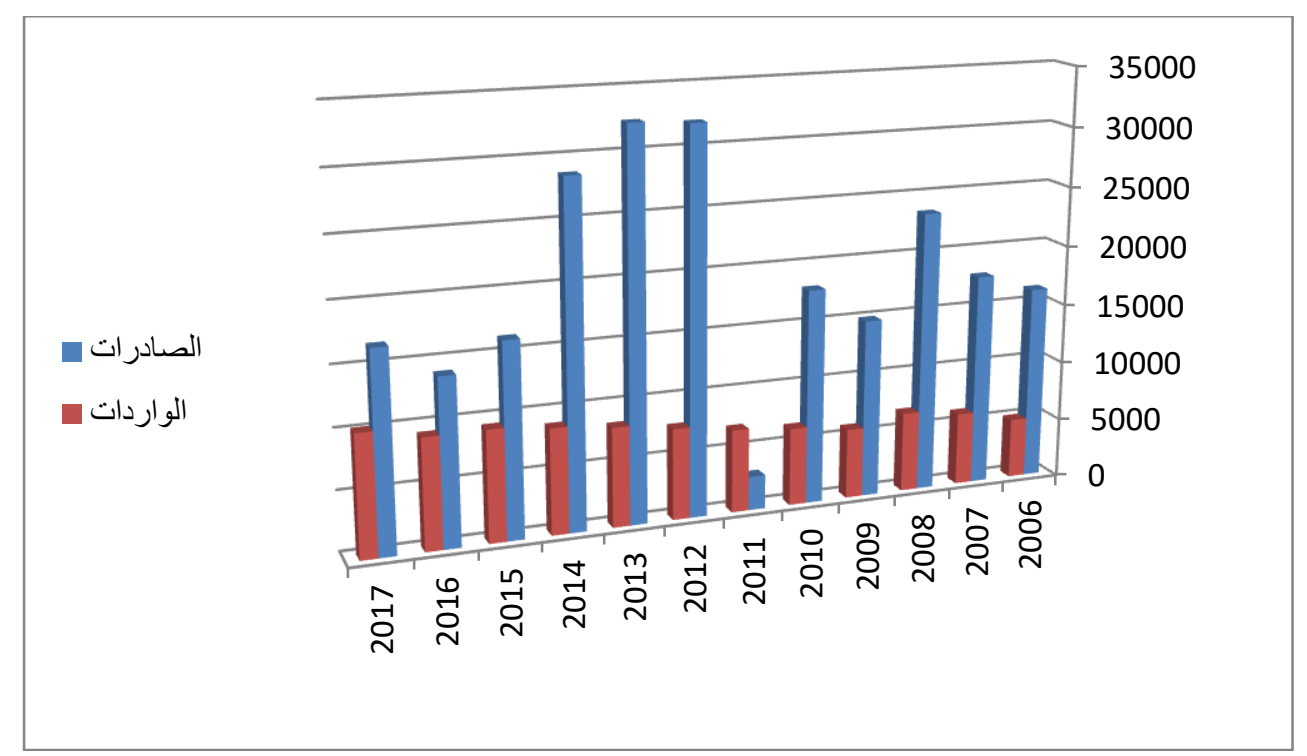

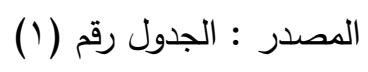

شكل رقم (1) تطور قيمة الصادرات والواردات الكويتية خلال الفترة $(r \cdot I V-r \cdot T)$

المطلب الثاني: تطور التركيبة السلعية للصادرات في الكويت خلال الفترة من $:(r \cdot 1 \Lambda-r \cdot 1 \varepsilon)$

اولأ: تطور التركيبة السلعية للصادرات في الكويت: يتضح من الجدول رقم (Y) أن التركيبة السلعية لصادرات الكويت خلال الفترة

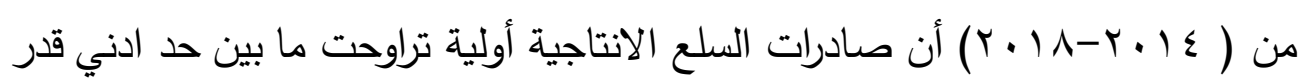

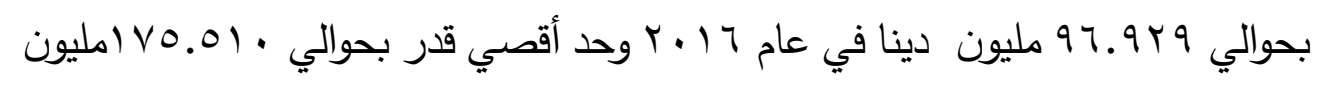

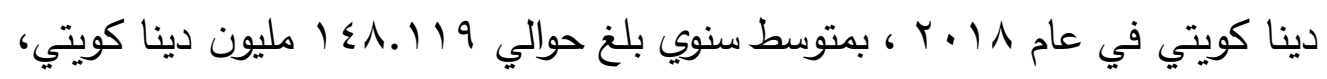

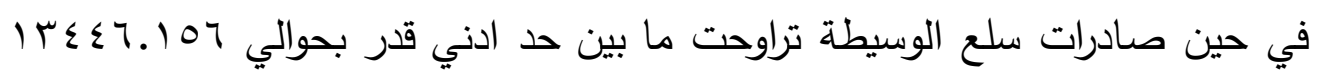




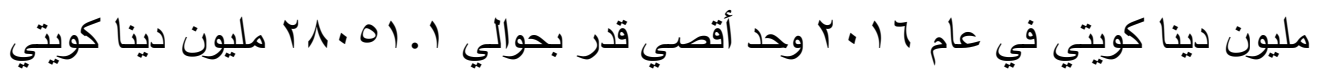

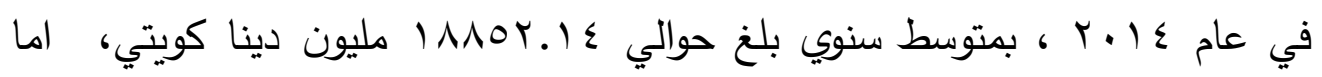
صادرات السلع الاستهلاكية تراوحت ما بين حد ادني قدر بحوالي ب ا. ب اء؛ مليون دينا

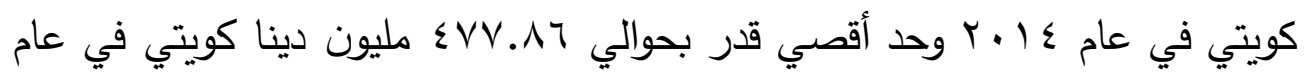

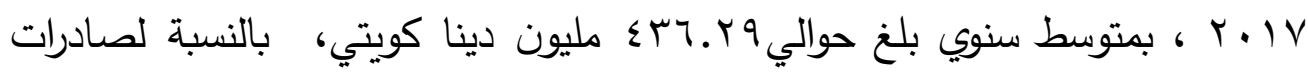
السلع الاخري تراوحت ما بين حد ادني قدر بحوالي مor . . مليون دينا كويتي في عام

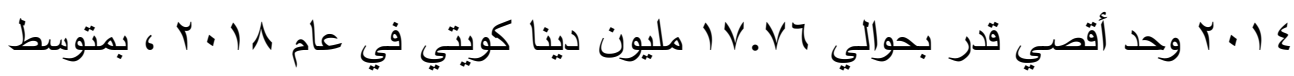
سنوي بلغ حوالي 97 . 7 مليون دينا كويتي، الجدول رقم (ץ) تطور التركيبة السلعية للصادرات في كويت خلال الفترة من

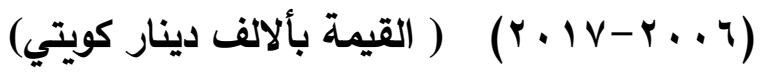

\begin{tabular}{|c|c|c|c|c|c|}
\hline الاجمالي & سلع أخري & سلع استهلاكية & سلع وسيطة & سلع إنتاجية & السنوات \\
\hline 28636493 & 152 & 413139 & 28051007 & 172195 & 2014 \\
\hline 16280209 & 792 & 461389 & 15680508 & 137520 & 2015 \\
\hline 13952081 & 898 & 408098 & 13446156 & 96929 & 2016 \\
\hline 16677510 & 15232 & 477864 & 16025973 & 158441 & 2017 \\
\hline 21671351 & 17764 & 420979 & 21057098 & 175510 & 2018 \\
\hline 19443529 & 6967.6 & 436293.8 & 18852148 & 148119 & المتوسط \\
\hline
\end{tabular}

المصدر: الادارة المركزية للاحصاء، إحصاءات التجارة الخارجية، الكويت، أعداد متفرقة. ثانياً: الاهمية النسبية التركيبة السلعية للصادرات في الكويت: 
يتضح من الجدول رقم (r) أن الاهمية النسبية للتركيبة السلعية لصادرات

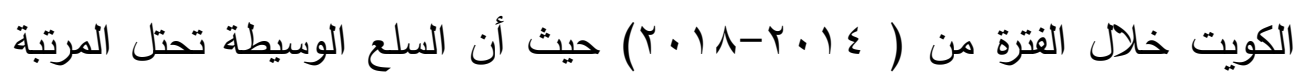
الأولى بالنسبة للمجموعات السلعية الأخرى من حيث أهميتها النسبية، حيث بلغت أدناها

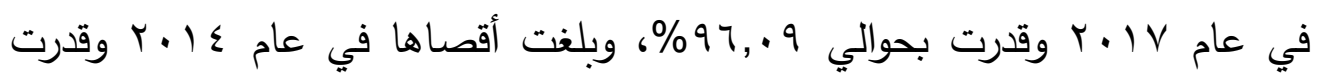

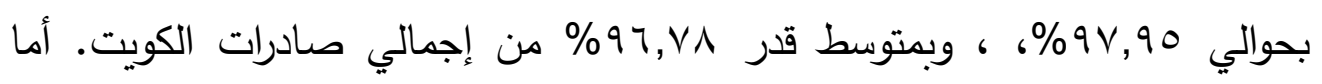
السلع الاستهلاكية تحتل المرتبة الثانية، حيث بلغت أدناها في عام ؟ا.ب وقدرت

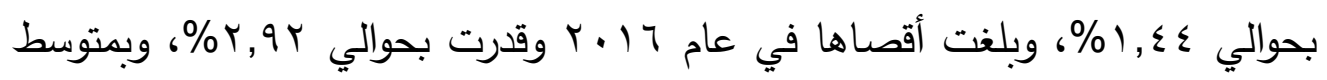

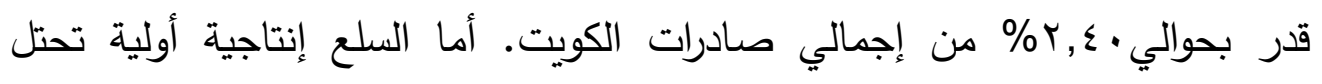

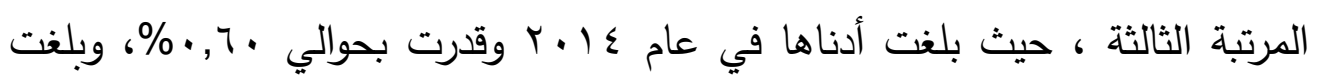

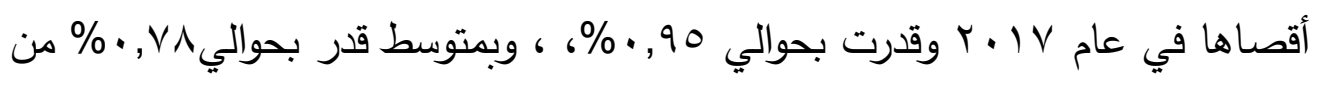
إجمالي صادرات الكويت، بينما سلع أخري احتلت المرتبة الاخيرة من حيث الاهمية النسبية لإجمالي صادرات الكويت.مما سبق نستنج أن صادرات السلع الوسيطة تأخذ نسبة كبيرة جدا تمثل حوالي \9\% من إجمالي الصادرات ، مقارنة بالصادرات الاخري التي تمثل حوالي ب\% من إجمالي صادرات الكويت كما هو موضع بالثكل رقم (r) الجدول رقم (ץ) الاهمية النسبية التركيبة السلعية للصادرات في الكويت خلال

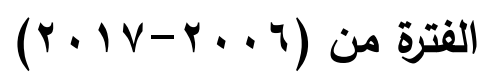

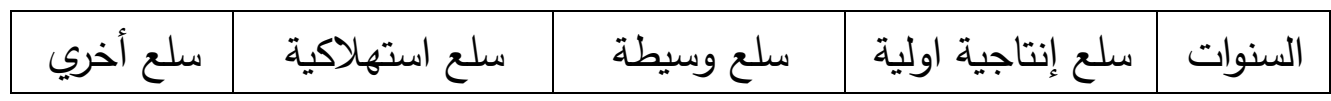




\begin{tabular}{|c|c|c|c|c|}
\hline 0.0005 & 1.44 & 97.95 & 0.6016 & 2014 \\
\hline 0.004 & 2.83 & 96.31 & 0.844 & 2015 \\
\hline 0.006 & 2.92 & 96.37 & 0.694 & 2016 \\
\hline 0.091 & 2.86 & 96.093 & 0.951 & 2017 \\
\hline 0.081 & 1.94 & 97.16 & 0.809 & 2018 \\
\hline 0.03 & 2.40 & 96.78 & 0.78 & المتوسط \\
\hline
\end{tabular}

المصدر : حسبت من بيانات جدول رقم (r)

المطلب الثالث: تطور التركيبة السلعية للواردات في الكويت خلال الفترة من (ع ا بـ$:(r \cdot 1 \Lambda$

إن الحديث عن الواردات يعني أن حجم الإنتاج المحلي لم يستطع تلبية احتياجات المستهلك، وقد يعود عدم القدرة هذا إلى قلة حجم الانتاج، لسعره أو لنوعيته، أو لأن الوضع الاقتصادي الحالي المتميز بتسهيل الواردات جعل هذه الأخيرة محل تفضيل على المنتوج المحلي حتى ولو كان هذا الأخير في درجة من الجودة.

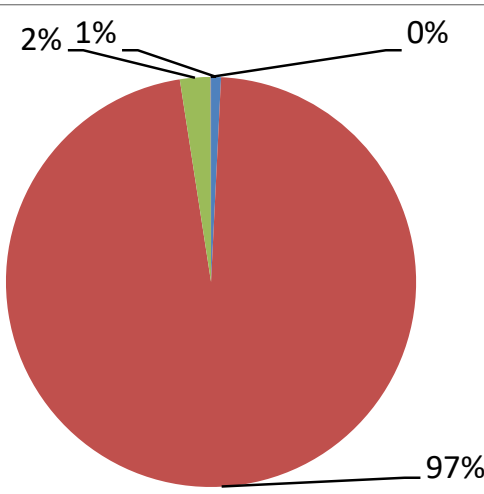

سلع إنتاجية اولية سلع وسيطة

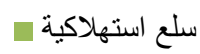

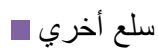
$97 \%$ 


\section{الثكل رقم (Y) يوضح الاهمية النسبية التركيبة السلعية للصادرات في الكويت

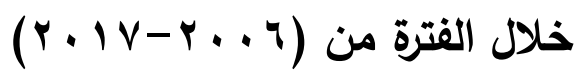

\section{اولأ: تطور التركيبة السلعية للواردات في الكويت:}

يتضح من الجدول رقم (ع) أن التركيبة السلعية للواردات الكويت خلال الفترة من

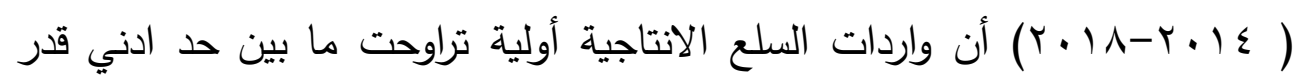

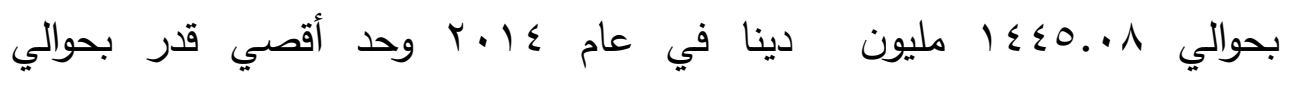

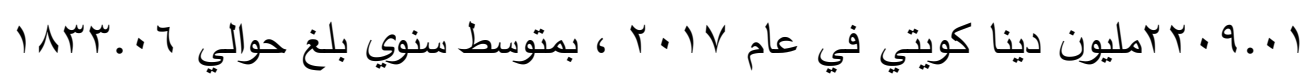
مليون دينا كويتي، في حين واردات سلع الوسيطة تراوحت ما بين حد ادني قدر بحوالي r.r.

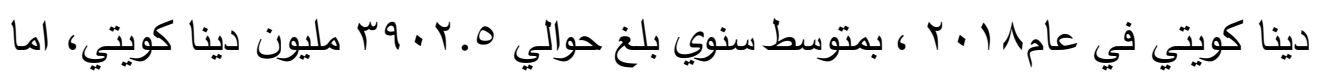
واردات السلع الاستهلاكية تراوحت ما بين حد ادني قدر بحوالي (9997 مليون دينا

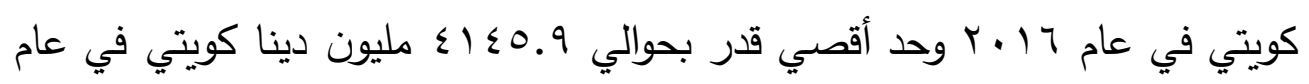

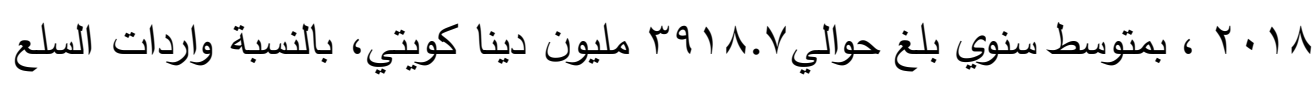

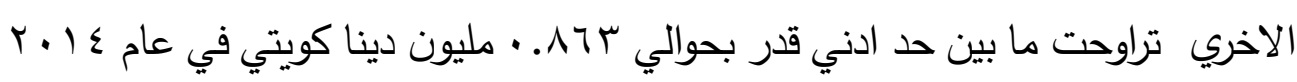

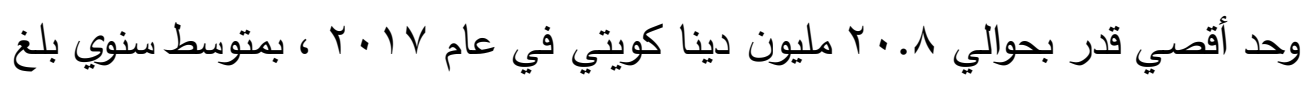
حوالي ع. ؛ ا مليون دينا كويتي، 
ثانياً: الاهمية النسبية التركيبة السلعية للواردات في الكويت: يتضح من الجدول رقم (0) وشكل رقم (r) أن الاهمية النسبية للتركيبة السلعية

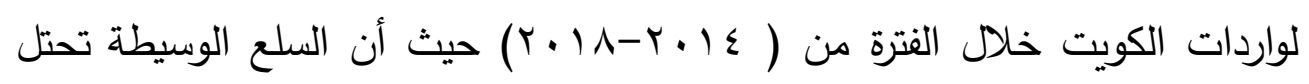
المرتبة الأولى بالنسبة للمجموعات السلعية الأخرى من حيث أهميتها النسبية، حيث بلغت

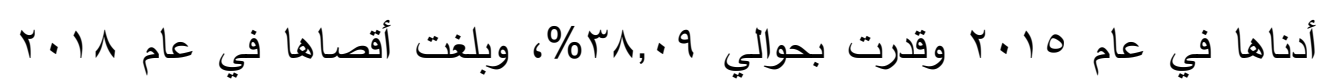

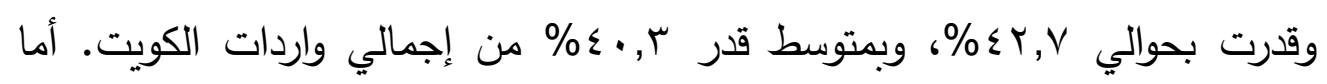
السلع الاستهلاكية تحتل المرتبة الثانية، حيث بلغت أدناها في عام V V. وقدرت

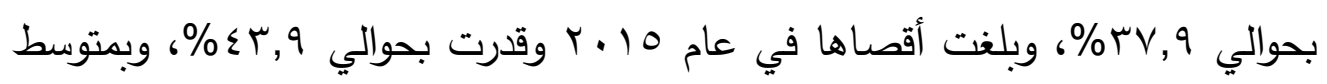

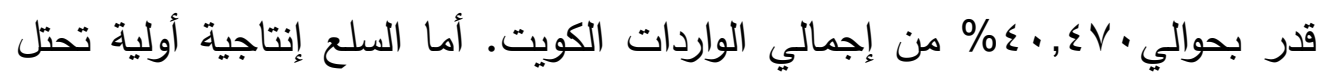
المرتبة الثالثة ، حيث بلغت أدناها في عام ع ( •r وقدرت بحوالي ع, ا (\%)، وبلغت

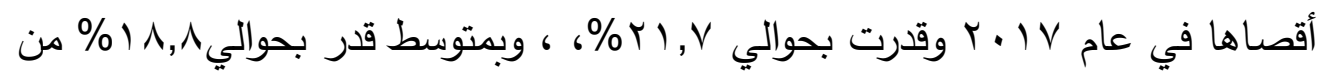
إجمالي واردات الكويت، بينما سلع أخري احتلت المرتبة الاخيرة من حيث الاهمية النسبية لإجمالي واردات الكويت.

الجدول رقم (؛) تطور التركيبة السلعية للواردات في كويت خلال الفترة من

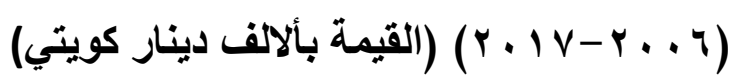

\begin{tabular}{|c|c|c|c|c|c|}
\hline الاجمالي & سلع أخري & استهلاكية & سلع وسيطة & سلع إنتاجية & السنوات \\
\hline
\end{tabular}


مجلة البحوث والدراسات الأفريقية ودول حوض النيل - جامعة أسوان - المجلا (ץ) العدد ( ) يناير ( ب • r م).

\begin{tabular}{|c|c|c|c|c|c|}
\hline 8829318 & 863 & 3820312 & 3563062 & 1445081 & 2014 \\
\hline 9316102 & 16390 & 4094226 & 3549319 & 1656167 & 2015 \\
\hline 9269308 & 17855 & 3699123 & 3722397 & 1829933 & 2016 \\
\hline 10182967 & 20819 & 3864046 & 4089089 & 2209013 & 2017 \\
\hline 10744686 & 14597 & 4115935 & 4589018 & 2025136 & 2018 \\
\hline 9668476.2 & 14104.8 & 3918728 & 3902577 & 1833066 & المتوسط \\
\hline
\end{tabular}

المصدر: الادارة المركزية للاحصاء، إحصاءات التجارة الخارجية، الكويت، أعداد

متقرقة.

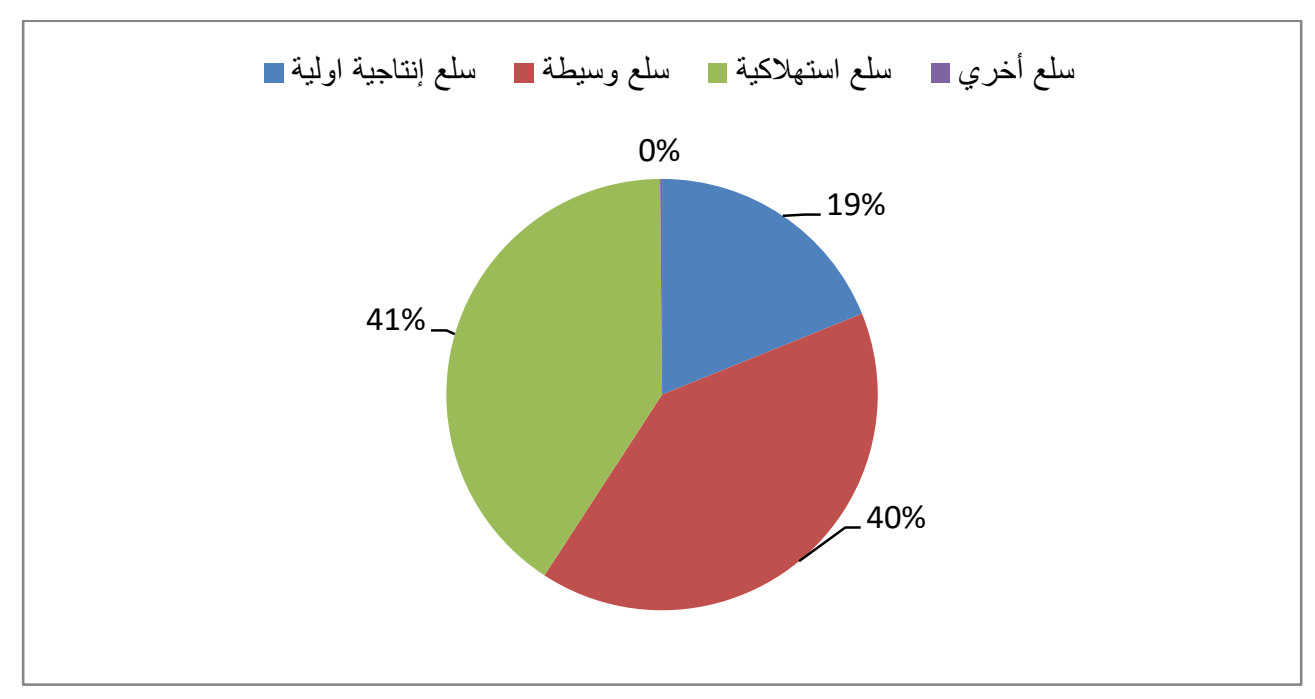

شكل رقم (ب) الاهمية النسبية التركيبة السلعية للواردات في الكويت

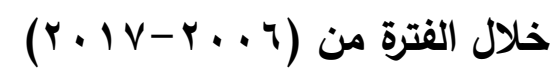

الجدول رقم (•) الاهمية النسبية التركيبة السلعية للواردات في الكويت خلال الفترة

$$
\text { من (r. r }
$$

\begin{tabular}{|c|c|c|c|c|}
\hline سلع أخري & سلع استهلاكية & سلع وسيطة & سلع إنتاجية اولية & السنوات \\
\hline 0.009 & 43.26 & 40.35 & 16.36 & 2014 \\
\hline
\end{tabular}




\begin{tabular}{|c|c|c|c|c|}
\hline 0.175 & 43.94 & 38.09 & 17.77 & 2015 \\
\hline 0.19 & 39.90 & 40.15 & 19.74 & 2016 \\
\hline 0.20 & 37.94 & 40.15 & 21.69 & 2017 \\
\hline 0.13 & 38.30 & 42.70 & 18.84 & 2018 \\
\hline 0.143 & 40.67 & 40.29 & 18.88 & المتوسط \\
\hline
\end{tabular}

المصدر : حسبت من جدول رقم (Y)

المبحث الثاني: التوزيع الجغرافي لصادرات و واردات الكويت حسب المناطق

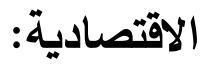

المطلب الاول: التوزيع الجغرافي للواردات الكويتية:

تثير بيانات الجدول رقم (†) أن مجموعة الدول الآسيوية تأتي في المرتبة

الاولي من حيث الواردات الكويتية، حيث أخذت قيمة الواردات منها، حيث بلغت أدناها

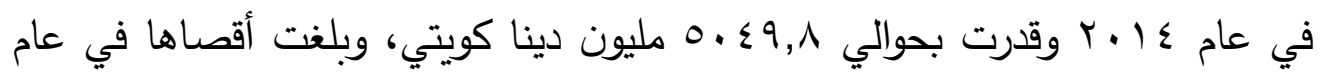

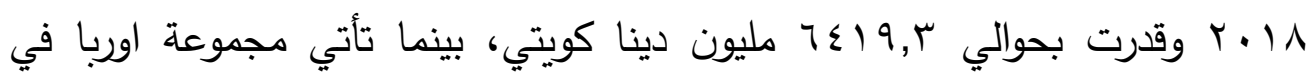

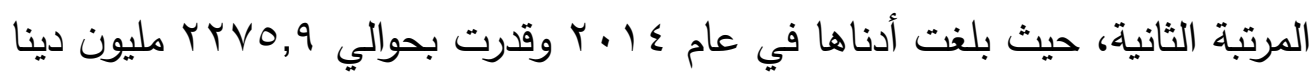

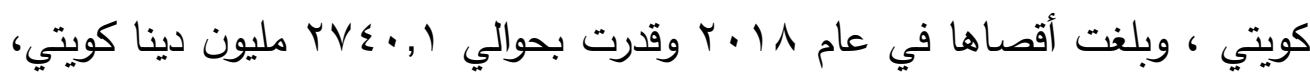
اما دول مجموعة امريكا الثمالية تأتي في المرتبة الثالثة من حيث ورادرت الكويت

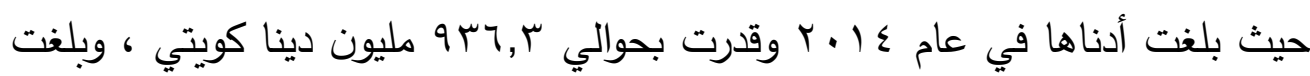

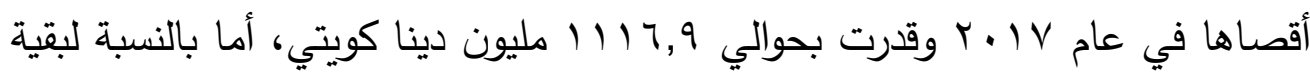
المناطق الاقتصادية كانت قيم واردات الكويت تتذبذب بين الارتفاع والانخفاض. 
جدول رقم (؟) التوزيع الجغرافي للواردات الكويتي حسب مجموعات الدول خلال

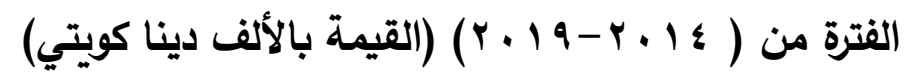

\begin{tabular}{|c|c|c|c|c|c|}
\hline 2018 & 2017 & 2016 & 2015 & 2014 & السنة \\
\hline 6419355 & 5810771 & 5382212 & 5442806 & 5049897 & مجموعة الدول \\
\hline 210239 & 211324 & 196843 & 232144 & 182234 & مجموعة الدول \\
\hline 126895 & 188128 & 178373 & 196306 & 204098 & مجموعة دول \\
\hline 1010314 & 1116953 & 960921 & 941695 & 936341 & مجموعة دول \\
\hline 231701 & 224034 & 197174 & 206645 & 174906 & مجموعة دول \\
\hline 2740104 & 2616377 & 2345227 & 2290773 & 2275974 & مجموعة \\
\hline
\end{tabular}

المصدر: الادارة المركزية للاحصاء، إحصاءات التجارة الخارجية، الكويت، أعداد متفرقة.

المطلب الثاني التوزيع الجغرافي للصادرات الكويتية:

تثير بيانات الجدول رقم (V) أن مجموعة الدول الآسيوية تأتي في المرتبة الاولي من حيث صادرات الكويتية، حيث أخذت قيمة الصادرات منها، حيث بلغت 


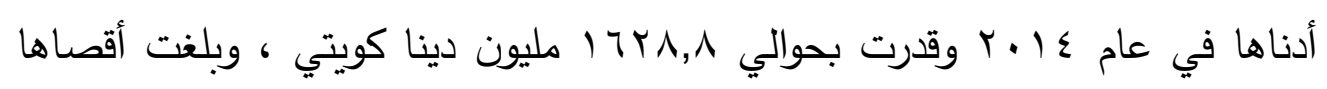

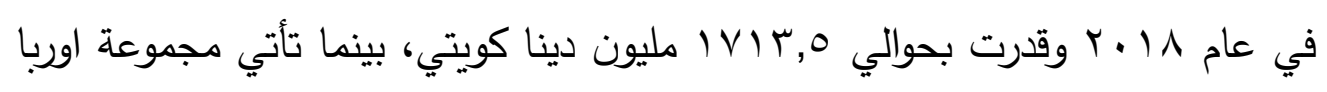

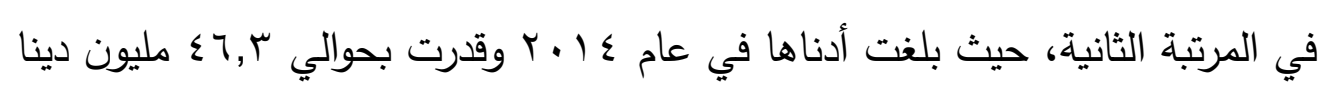

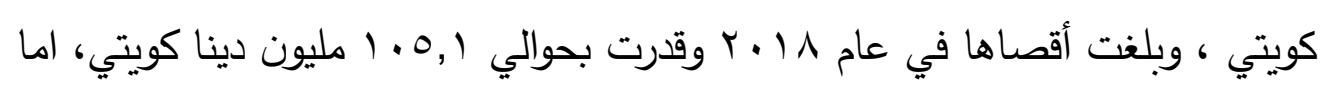
دول مجموعة امريكا الثمالية تأتي في المرتبة الثالثة من حيث ورادرت الكويت حيث

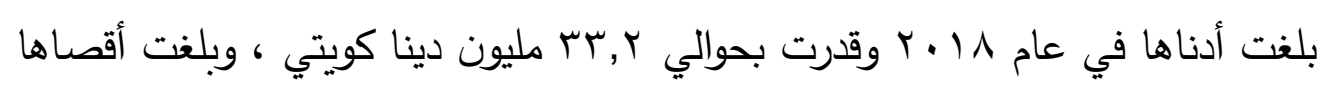
في عام 10 ب وقدرت بحوالي ع, ا7 مليون دينا كويتي، أما بالنسبة لبقية المناطق الاقتصادية كانت قيم واردات الكويت تتنذب بين الارتفاع والانخفاض.

الجدول رقم (V) التوزيع الجغرافي للصادرات الكويت حسب مجموعات الدول

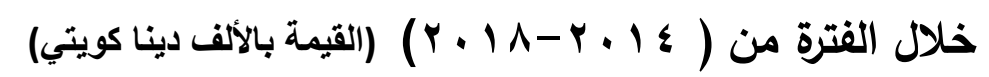

\begin{tabular}{|c|c|c|c|c|c|}
\hline 2018 & 2017 & 2016 & 2015 & 2014 & السنة \\
\hline 1713577 & 1424428 & $\begin{array}{c}12241 \\
6\end{array}$ & $\begin{array}{c}149255 \\
4\end{array}$ & 1628804 & مجموعة الدول الآسيوية \\
\hline 74233 & 37114 & 39812 & 52597 & 37167 & مجموعة الدول الأفريقية \\
\hline 13861 & 6404 & 4826 & 2991 & 4757 & مجموعة دول اوقيانوسيا \\
\hline 33209 & 43257 & 39156 & 61370 & 40349 & مجموعة دول أمريكا \\
\hline 20320 & 29279 & 12317 & 19,754 & 45,434 & مجموعة دول امريكا \\
\hline 85109 & 103,440 & 10507 & 66872 & 46334 & مجموعة أوروبا \\
\hline
\end{tabular}




\begin{tabular}{|l|l|l|l|l|l|}
\hline & & 6 & & & \\
\hline & & & & & \\
\hline
\end{tabular}

المصدر: الادارة المركزية للاحصاء، إحصاءات التجارة الخارجية، الكويت، أعداد

متفرقة.

المطلب الثالث: أهم شركاء الكويت للصادرات خلال عام ^ 1 ـ ץ: يظهر لنا الجدول رقم (^) والثكل رقم (ع) أهم الدول المتعاملة مع الكويت في مجال الصادرات، ويوضح أهم الدول التي تمثل أسواق للكويت في الخارج ، نلاحظ أن الهند تحتل صدارة المتعاملين مع الكويت في إطار الصادرات لعام ^ \. ب حيث تصدر

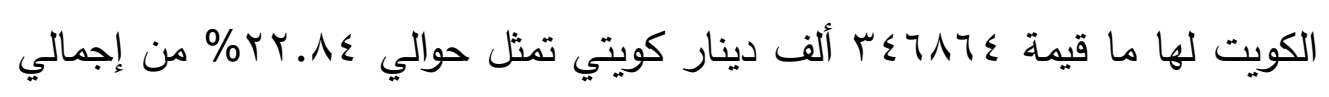
الصادرات، ويليها في الترتيب كل من الصين العراق والامارات والمملكة العربية السعودية حيث تصدر الكويت لهما ما قيمة حوالي MN.VV YNVTI

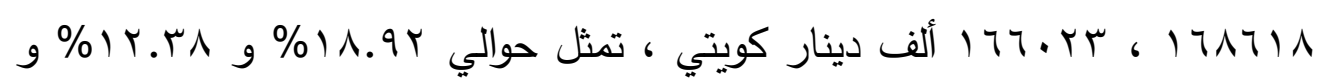

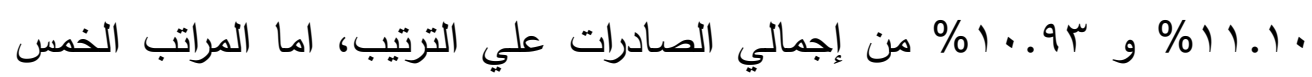
الاخيرة جاءت كل من قطر و باكستان و عمان و تركيا و الولايات المتحدة الامريكية

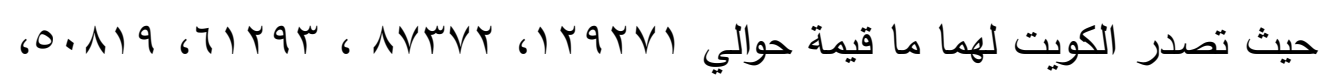

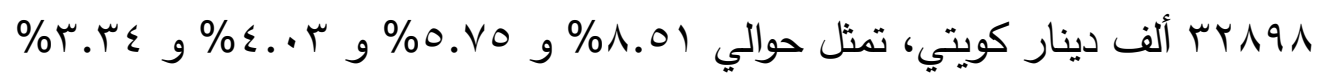
و 1 ـr\% من إجمالي الصادرات علي الترتيب.

الجدول رقم (^) يوضح أهم شركاء الكويت للصادرات خلال عام ^ 1 ـ r 
(القيمة بالالف دينار كويتي)

\begin{tabular}{|c|c|c|c|}
\hline$\%$ & القيمة & الدول & الرقم \\
\hline 22.84 & 346864 & الهند & 1 \\
\hline 18.92 & 287319 & الصين & 2 \\
\hline 12.38 & 188077 & العراق & 3 \\
\hline 11.10 & 168618 & الامارات & 4 \\
\hline 10.93 & 166023 & المملكة العربية & 5 \\
\hline 8.51 & 129271 & قطر & 6 \\
\hline 5.75 & 87372 & باكستان & 7 \\
\hline 4.03 & 61293 & عمان & 8 \\
\hline 3.34 & 50819 & تركيا & 9 \\
\hline 2.16 & 32898 & الولايات المتحدة & 10 \\
\hline 100 & 1518554 & & المجموع \\
\hline
\end{tabular}

المصدر : الادارة المركزية للاحصاء، إحصاءات التجارة الخارجية، الكويت، أعداد

متقرقة.

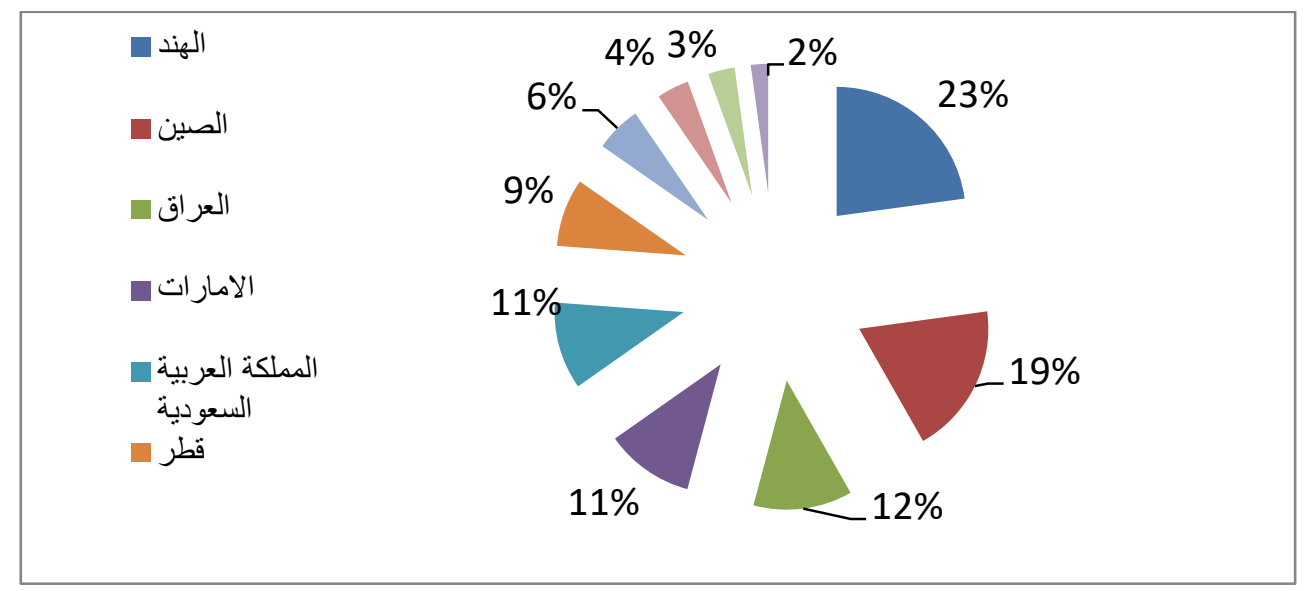




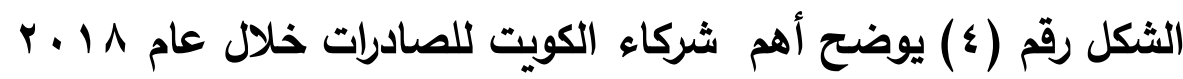

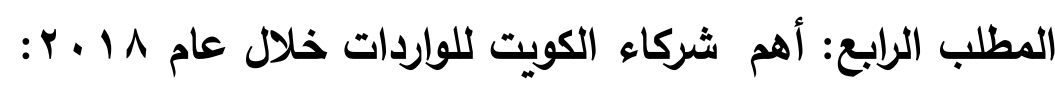
يظهر لنا الجدول رقم (9) والثكل رقم (0) أهم الدول الدتعاملة مع الكويت في مجال الاستيراد، إذ يمكن من خلال معرفة مدي ارتباط الكويت بالأسواق الخارجية ومعرفة مدي الاعتماد علي دولة واحدة أو تكتل اقتصادي واحد في جلب المنتجات التي بحاجة اليها ، نلاحظ أن الصين تحتل صدارة المتعاملين مع الكويت في إطار

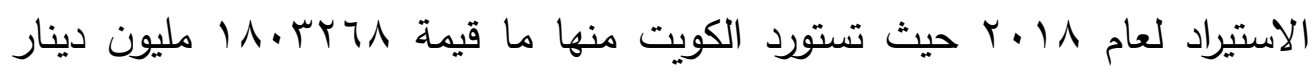

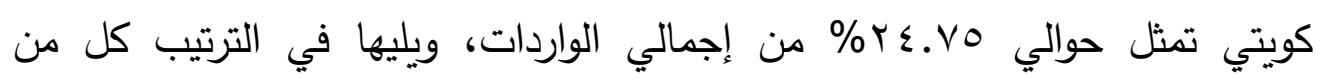
الولايات المتحدة الامريكية والامارات و اليابان والمانيا حيث تستود الكويت منهما ما

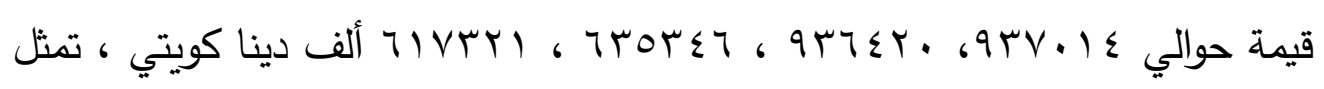

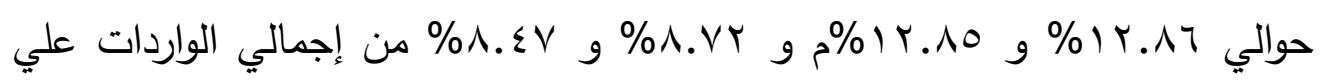
الترتيب، اما المراتب الخمس الاخيرة جاءت كل من المملكة العربية السعودية و الهند و ايطاليا و كوريا الجنوبية و المملكة المتحدة، حيث تستود الكويت منهما ما قيمة حوالي

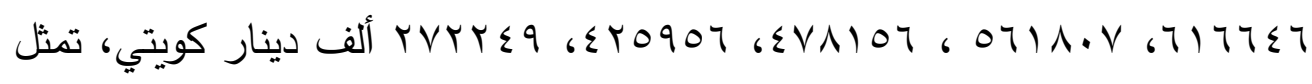

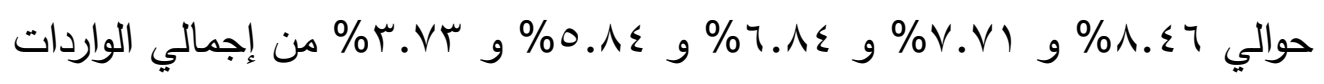
علي الترتيب.

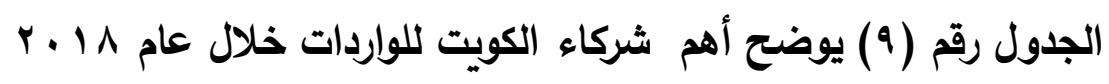


(القيمة بالالف دينار كويتي)

\begin{tabular}{|c|c|c|c|}
\hline$\%$ & القيمة & الدول ل & 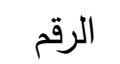 \\
\hline 24.75 & 1803268 & الصين الصين & 1 \\
\hline 12.86 & 937014 & الولايات المتحدة الامريكية & 2 \\
\hline 12.85 & 936420 & الامارات & 3 \\
\hline 8.72 & 635346 & اليابان & 4 \\
\hline 8.47 & 617321 & المانيا & 5 \\
\hline 8.46 & 616646 & المملكة العربية السعودية & 6 \\
\hline 7.71 & 561807 & الهند & 7 \\
\hline 6.56 & 478156 & ايطاليا & 8 \\
\hline 5.84 & 425956 & كوريا الجنوبية & 9 \\
\hline 3.73 & 272249 & المملكة المتحدة & 10 \\
\hline 100 & 7284183 & & المجموع \\
\hline
\end{tabular}

المصدر : الادارة المركزية للاحصاء، إحصاءات التجارة الخارجية، الكويت، أعداد متفرقة.

| الصين

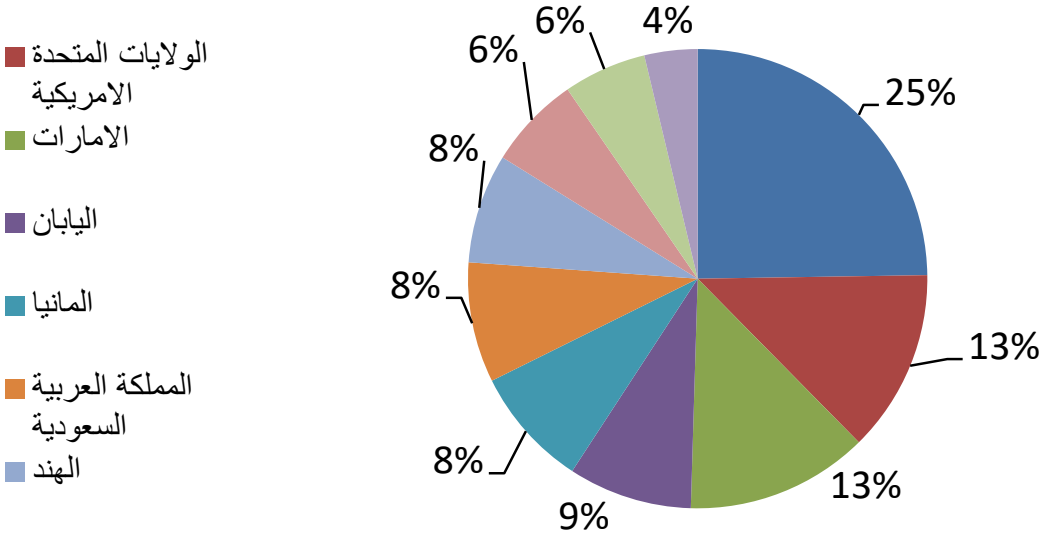

الثكل رقم (0) يوضح أهم شركاء الكويت للواردات خلال عام 1 ا . r 
مجلة البحوث والاراسات الأفريقية ودول حوض النيل - جامعة أسوان - المجلد (r) العدد ( ) يناير ( r م r م). 


\section{الـــــراجع:}

1- عبدالهادي عبد القادر سويفي، التجارة الخارجية، كلية التجارة ، جامعة

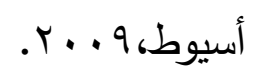

r- موسي سعيد مطر وآخرون، التجارة الخارجية ، دار الصفاء للنشر والتوزيع ،

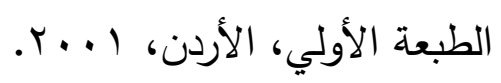

r- بني يحي ابتسام، محددات التدفق التجاري الدولي في ظل البيئة الدولية الجديدة للتجارة العالمية، رسالة ماجستير ، جامعة سطيف. Y I . . ع- الادارة المركزية للاحصاء، إحصاءات التجارة الخارجية، الكويت. 